\title{
Topical issue on "Corrosion of metals and physicochemical characterization of passive and corroding surfaces" devoted to celebrate the 72nd birthday of Dr. Masahiro Seo
}

\author{
Hiroki Habazaki ${ }^{1}$ Su-Il Pyun ${ }^{2}$
}

Published online: 1 October 2015

(C) Springer-Verlag Berlin Heidelberg 2015

This topical issue on "Corrosion of metals and physicochemical characterization of passive and corroding surfaces" is dedicated to the 72nd birthday of Dr Masahiro Seo, Professor Emeritus of Hokkaido University.

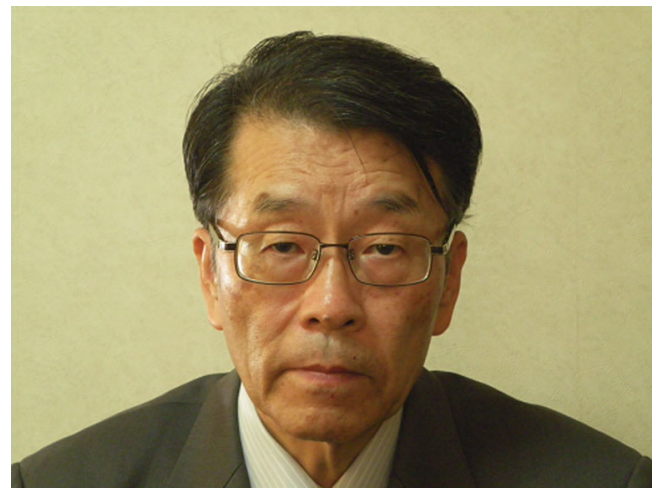

Professor Masahiro Seo was born on January 11, 1943, in Kanazawa, Ishikawa-prefecture, Japan. He studied physical chemistry at Hokkaido University and obtained his Dr. Eng. Degree in 1970. His doctoral thesis was entitled "Physicochemical Study of Silver-Oxygen-Ethylene Systems," and this work was supervised by the famous corrosion scientist Pro-

Hiroki Habazaki

habazaki@eng.hokudai.ac.jp

Su-Il Pyun

sipyun@kaist.ac.kr

1 Faculty of Engineering, Hokkaido University, Sapporo, Hokkaido 060-8628, Japan

2 Korea Advanced Institute of Science and Technology, \#373-1 Guseong-Dong, Yuseong-Gu, Daejeon 305-701, Republic of Korea fessor Norio Sato. Then, he worked in the laboratory of Professor Norio Sato as a Research Associate (1970-1976) and an Associate Professor (1976-1990) with his main research in this period relating to surface analysis of passive films on iron and iron-base alloys. From October 1972 for 2 years, he was a Visiting Research Associate at the Department of Metallurgy, Ohio State University, where he worked with the well-known corrosion scientist Professor R.W. Staehle. His most cited paper on Auger electron spectroscopy analysis of oxide films on iron was conducted during this period [1]. In 1990, he became full Professor at the Faculty of Engineering, Hokkaido University as a successor of Professor Norio Sato. In 2006, he retired from Hokkaido University, but he is still very active in his research.

He has a broad range of research interests and achievements in corrosion and interfacial electrochemistry. He has introduced novel approaches for his studies, including Auger electron spectroscopy for characterization of passive films, Piezoelectric detection system and bending beam method for surface stress measurements of metal electrodes [2-4], QCM for corrosion of metal thin films [5], scanning electrochemical microscopy for in situ corrosion studies [6,7], nano-indentation and nano-scratching techniques combined with AFM for mechano-electrochemisty of passive metal surfaces $[8,9]$, and recent in situ X-ray absorption spectroscopy for UPD study [10]. In particular, his pioneering mechano-electrochemisty is a powerful approach for further deep understanding of the growth and breakdown of surface oxide films on metals. He has published more than 200 peer-reviewed papers.

He has been contributing to international and domestic scientific societies. He was a member of the Executive Committee of Corrosion Division of The Electrochemical 
Society (2000-2002), an Editor-in-Chief of the Journal of Surface Finishing Society of Japan, and President of the Japan Society of Corrosion Engineering (2005-2006). He has conducted many international collaboration researches with, for instance, Professor S.I. Pyun (Korea), Professor G.G. Lang (Hungary), Professors G. Hultquist and C. Leygraf (Sweden), Professor H. W. Smyrl (USA), and Professor J. Weissmuller (Germany). Many foreign and Japanese $\mathrm{PhD}$ students and postdocs studying in his laboratory are now actively working in corrosion and electrochemistry fields worldwide. Some of them contributed to this topical issue.

As guest editors of this topical issue, we would like to express our sincere gratitude for the warm response of collaborators and friends of Professor Masahiro Seo that contributed to this topical issue. We really hope that Professor Masahiro Seo will enjoy reading the papers of this issue, in which many leading-edge investigations related to corrosion and characterization of passive and corroding metal surfaces are collected.

Let us all wish Professor Masahiro Seo good health and much success in his further scientific pursuits.

On behalf of the students, collaborators, and friends of Professor Masahiro Seo,

Hiroki Habazaki

Su-Il Pyun

\section{References}

1. Seo M, Lumsden JB, Staehle RW (1975) AES analysis of oxidefilms on iron. Surf Sci 50:541-552

2. Lang GG, Seo M (2000) On the electrochemical applications of the bending beam method. J Electroanal Chem 490:98-101

3. Seo M, Jiang XC, Sato N (1987) Piezoelectric response to surface stress change of gold electrode in sulfate aqueous-solutions. J Electrochem Soc 134:3094-3098

4. Seo M, Makino T, Sato N (1986) Piezoelectric response to surface stress change of platinum-electrode. J Electrochem Soc 133:11381142

5. Seo M, Yoshida K, Noda K (1995) An EQCM study on corrosion of iron thin film in deaerated neutral solutions. Mater Sci Forum 192-194:755-763

6. Fushimi K, Okawa T, Azumi K, Seo M (2000) Heterogeneous growth of anodic oxide film on a polycrystalline titanium electrode observed with a scanning electrochemical microscope. J Electrochem Soc 147:524-529

7. Fushimi K, Seo M (2001) An SECM observation of dissolution distribution of ferrous or ferric ion from a polycrystalline iron electrode. Electrochim Acta 47:121-127

8. Chiba M, Seo M (2003) Mechanoelectrochemical properties of passive iron surfaces evaluated by an in situ nanoscratching test. J Electrochem Soc 150:B525-B529

9. Seo M, Chiba M (2001) Nano-mechano-electrochemistry of passive metal surfaces. Electrochim Acta 47(1-2):319-325

10. Seo M, Fushimi K, Aoki Y, Habazaki H, Inaba M, Yokomizo M, Hayakawa T, Nakayama T (2012) In situ X-ray absorption spectroscopy for identification of lead species adsorbed on a nickel surface in acidic perchlorate solution. J Electroanal Chem 671:7-15 